\title{
Pre-existing diabetes and lung cancer prognosis
}

\author{
Juhua Luo*,1, Michael Hendryx ${ }^{2}$, Lihong $\mathrm{Qi}^{3}$, Gloria YF Ho ${ }^{4}$ and Karen L Margolis ${ }^{5}$ \\ ${ }^{1}$ Department of Epidemiology and Biostatistics, School of Public Health, Indiana University Bloomington, Bloomington, IN, USA; \\ ${ }^{2}$ Department of Applied Health Science, School of Public Health, Indiana University Bloomington, Bloomington, IN, USA; \\ ${ }^{3}$ Department of Public Health Science, School of Medicine, University of California, Davis, CA, USA; ${ }^{4}$ Department of Occupational \\ Medicine, Epidemiology \& Prevention, Feinstein Institute for Medical Research, Northwell Health, Great Neck, NY, USA and \\ ${ }^{5}$ HealthPartners Institute for Education and Research, Box 1524, Mailstop, 21111R, Minneapolis, MN, USA
}

Background: The aims of this study are to investigate the impact of pre-existing diabetes and diabetes treatments on lung cancer prognosis.

Methods: A total of 2484 women with confirmed incident lung cancer from the Women's Health Initiative were followed for an average of 2.9 years through the date of death or 29 August 2014.

Results: Compared with women with lung cancer but without diabetes, women with lung cancer and diabetes had significantly increased risk of overall mortality ( $\mathrm{HR}=1.27,95 \% \mathrm{Cl}$ : 1.07-1.50). Women with diabetes receiving insulin or metformin or women who had long duration of diabetes also had increased risk of overall mortality.

Conclusions: Our large prospective study provides evidence that pre-existing diabetes is associated with poor overall survival among women with lung cancer, but do not support the hypothesis that metformin use may have a protective effect in women with lung cancer and diabetes.

Diabetes may influence lung cancer progression and outcome by several mechanisms, including hyperinsulinemia, hyperglycaemia, or chronic inflammation, which have been shown to be associated with cell proliferation and cancer progression (Morss and Edelman, 2007; Garcia-Jimenez et al, 2014). In addition, pre-existing diabetes may have adverse effects on lung cancer outcome by influencing clinical decisions regarding lung cancer treatment or response to treatment (van de Poll-Franse et al, 2007).

Studies of mortality outcomes for lung cancer participants with pre-existing diabetes are conflicting (De Giorgio et al, 2000; Park et al, 2006; Hatlen et al, 2011; Shieh et al, 2012). Previous studies were retrospective and often only examined overall mortality. Thus, prospective studies are needed to clarify whether diabetes influences overall and cancer-specific mortality among lung cancer participants.

Data regarding effects of diabetic therapy on lung cancer outcomes are sparse and retrospective. Some studies (Tan et al, 2011; Lin et al, 2015) found that metformin may improve chemotherapy outcomes for participants who have non-small cell lung carcinoma (NSCLC) compared with other therapies (e.g. insulin, sulfonylureas). Other studies found that metformin use has no impact or worsens survival for lung cancer participants (Mazzone et al, 2012; Ahmed et al, 2015).

In the current study, we used Women's Health Initiative (WHI) data to compare lung cancer outcomes between participants with and without pre-existing diabetes, and between metformin and non-metformin treatment.

\section{METHODS}

Study population. The WHI enrolled 161808 postmenopausal women aged 50-79 years between 1993 and 1998 from 40 clinical centres throughout the United States into an observational study (OS) and three clinical trials (CT) (Hays et al, 2003; Jackson et al, 2003; Langer et al, 2003; Ritenbaugh et al, 2003; Stefanick et al, 2003).

*Correspondence: Dr J Luo; E-mail: juhluo@indiana.edu

Received 4 January 2016; revised 13 April 2016; accepted 26 April 2016; published online 19 May 2016

(C) 2016 Cancer Research UK. All rights reserved 0007-0920/16 
Incident lung cancer cases were identified by self-report questionnaires with all cases confirmed by medical record review. All incident lung cancer cases diagnosed by August 2014 were initially included in the study $(N=2800)$. We excluded 296 women with a history of any cancer at baseline (other than non-melanoma skin cancer), 7 type 1 diabetes cases based on self-report of a diabetes diagnosis at age 21 years or younger, and 13 women with missing values for diabetes at baseline and follow-up. After exclusions, a total of 2484 cases were available for analysis. By August 2014, 1347 died from lung cancer among 1824 deaths. Available tumour characteristics include stage, size, positive lymph nodes, grade, and histology.

\section{Measurements}

Outcomes. Overall mortality and lung cancer-specific mortality. Cause of death was classified by trained physician adjudicators based on available documents that included medical records and death certificate (WHI, 2016).

Diabetes status, diabetes therapies, and diabetes duration. Prevalent diabetes at enrollment was defined as a positive answer to the question 'did a doctor ever say that you had sugar diabetes or high blood sugar when you were not pregnant'. Age at first diagnosis was also self-reported. Medically treated diabetes at enrollment was defined as reporting ever having been treated for diabetes with pills or insulin shots. Initiation of diabetes treatment, but not a new diagnosis of diabetes, was assessed at follow-up visits at year 3 for participants in the OS and at years 1, 3, 6, and 9 for those in the CT. As such, in this analysis, incident diabetes was defined as treated diabetes. At baseline and follow-up visits, participants were asked to bring all current prescription medications. Prescription of anti-diabetic medications was categorised into insulin (used alone or with other oral medications), metformin (used alone or with other oral medications), or only used other anti-diabetic medications. We determined diabetes status up to the date of lung cancer diagnosis. Duration of diabetes was estimated from the date or age of the first diabetes diagnosis to the date of lung cancer diagnosis. Self-reported diabetes in the WHI has been found to be reliable (Margolis et al, 2008; Jackson et al, 2013).

Demographics, lung cancer risk factors, and other covariates. Covariates included age at lung cancer diagnosis, tumour stage, and baseline variables including race/ethnicity, education, body mass index (BMI), smoking, physical activity, alcohol intake, participation in OS or different CT arms. Cumulative number of comorbid conditions such as cardiovascular diseases, depression, osteoporosis and arthritis, and so on, was updated the date of lung cancer diagnosis and categorised as $0,1,2,3$, and $\geqslant 4$. Measurement of these variables is described in detail in Table 1.
Statistical analysis. Multivariable Cox proportional hazards regression analysis was employed to estimate hazard ratios for overall mortality according to diabetes status after adjusting for covariates. The proportional subdistribution hazard model proposed by Fine and Gray (Fine and Gray, 1999) was used to estimate hazard ratios for lung cancer-specific mortality associated with diabetes status by accounting for non-lung cancer mortality as competing risk.

In addition, we used a subset (1053) of WHI data linked with claims data among women aged 65 years or older at cancer diagnosis to further adjust for cancer treatment as a sensitivity analysis.

\section{RESULTS}

Of the 2484 women with lung cancer, 276 (11.1\%) had prevalent or incident diabetes before lung cancer diagnosis. Compared with women without diabetes, women with diabetes were significantly more likely to be members of non-White race/ethnicity groups, have a higher BMI, be physically inactive, have no current alcohol use, be less educated, and have greater number of comorbid conditions. However, there was no substantial difference between the diabetes group and no diabetes group in age at cancer diagnosis and smoking habits (Table 1).

Women with or without diabetes had no statistically significant differences on tumour characteristics (Supplementary Table 1). Compared with women without diabetes, women with diabetes had significantly increased risk of overall mortality $(\mathrm{HR}=1.27$, 95\% CI: 1.07-1.50). The unadjusted Kaplan-Meier survival curves stratified by diabetes status are provided online (Supplementary Figure $1 \mathrm{~A}$ and $\mathrm{B}$ ), as is overall mortality in relation to diabetes stratified by stage (Supplementary Table 2). Women who received insulin or metformin or with diabetes duration longer than 7 years prior to lung cancer diagnosis had significantly higher risk of overall mortality (Table 2).

Women who received insulin had significantly increased risk of cancer-specific mortality after adjusting for age and stage $(\mathrm{HR}=1.45$, 95\% CI: 1.00-2.11). Further adjustment for other potential risk factors did not change the magnitude substantially $(\mathrm{HR}=1.52$, 95\% CI: 0.99-2.34), but the effect became nonsignificant. In addition, we did not find significant associations between lung cancer-specific mortality and diabetes, metformin use, or diabetes duration (Table 3).

We conducted two sensitivity analyses: (1) restricting analyses to only non-small cell lung carcinoma (Supplementary Table 3); (2) using WHI linked with CMS data and restricting the analysis to women who were 65 years or older and further adjusting for cancer treatment (including surgery, radiation and chemotherapy). All results were similar.

Table 1. Baseline characteristics of 2484 patients with lung cancer by diabetes status

\begin{tabular}{|c|c|c|c|}
\hline & No diabetes (2208 patients) & Diabetes (276 patients) & $P$-value \\
\hline Age at breast cancer diagnosis (mean, s.d.) & $72.9(7.3)$ & $73.2(6.6)$ & 0.6 \\
\hline White (not of Hispanic origin) (\%) & $1992(90.2)$ & $216(78.3)$ & $<0.0001$ \\
\hline $\mathrm{BMI}$ at baseline (mean, $\mathrm{kg} \mathrm{m}^{-2}$, s.d.) & $26.8(5.2)$ & $31.2(6.0)$ & $<0.0001$ \\
\hline METs_hours per week ${ }^{a}$ (mean, s.d.) & $12.3(14.3)$ & $9.1(12.3)$ & 0.0002 \\
\hline Current smoking (\%) & $615(27.9)$ & $72(26.1)$ & 0.4 \\
\hline Current alcohol drinker (\%) & $1702(77.1)$ & $168(60.9)$ & $<0.0001$ \\
\hline Co-morbidity (4 or more) & 715 (32.4) & $157(56.9)$ & $<0.0001$ \\
\hline
\end{tabular}


Table 2. HRs for overall mortality in relation to diabetes among 2484 patients with lung cancer

HR $(95 \% \mathrm{Cl})$ for total mortality

\begin{tabular}{|c|c|c|c|}
\hline & Deaths (total cases) & Age and stage adjusted & Multivariable adjusted $^{a}$ \\
\hline No diabetes & $1623(2208)$ & 1 & 1 \\
\hline Diabetes & $201(276)$ & $1.27(1.10,1.47)$ & $1.27(1.07,1.50)$ \\
\hline \multicolumn{4}{|c|}{ Duration of diabetes at cut-point of median value } \\
\hline $\begin{array}{l}<7 \text { years } \\
\geqslant 7 \text { years }\end{array}$ & $\begin{array}{r}97(143) \\
104(133)\end{array}$ & $\begin{array}{l}1.24(1.01,1.52) \\
1.30(1.07,1.59)\end{array}$ & $\begin{array}{l}1.22(0.98,1.53) \\
1.31(1.05,1.64)\end{array}$ \\
\hline \multicolumn{4}{|c|}{ Type of diabetic drugs in medication inventory } \\
\hline $\begin{array}{l}\text { Insulin (alone or with oral medication) } \\
\text { Metformin } \\
\text { Other drugs } \\
\text { Untreated/drugs unknown }\end{array}$ & $\begin{array}{l}37(46) \\
50(62) \\
47(56) \\
67(112)\end{array}$ & $\begin{array}{l}1.51(1.09-2.10) \\
1.54(1.16-2.04) \\
1.26(0.94-1.69) \\
1.05(0.82-1.34)\end{array}$ & $\begin{array}{l}1.54(1.06-2.23) \\
1.48(1.09-2.00) \\
1.29(0.94-1.77) \\
1.06(0.82-1.38)\end{array}$ \\
\hline
\end{tabular}

${ }^{a}$ Model adjusted age at diagnosis ( $\left.<55,55-59,60-64,65-69,70-74, \geqslant 75\right)$, stage (localised, regional, and distant), race/ethnicity (American Indian or Alaska Native, Asian or Pacific Islander, Black or African American, Hispanic/Latino, non-Hispanic white, and other), education (high school or less, some college/technical training, college or some post-college, and master or higher), BMI ( $<18.5,18.5-24.9,25.0-29.9,30.0-34.9,35.0-39.9,>40)$, physical activity (metabolic equivalent task (MET) - hours per week: $<5,5-<10,10-<20,20-<30, \geqslant 30)$ ), alcohol intake (nondrinker, past drinker, $<1$ drink per month, and current drinker-including frequency: $<1$ drink per month, 1 drink per month to $<1$ drink per week, 1 to $<7$ drinks per week, $>7$ drinks per week), smoking (never, former, and current), and comorbidity $(0,1,2,3,4$, or more) and different WHI clinical assignments.

\section{Table 3. HRs for lung cancer-specific mortality in relation to diabetes among 2484 patients with lung cancer}

\begin{tabular}{|c|c|c|c|}
\hline & \multicolumn{3}{|c|}{ HR $(95 \% \mathrm{Cl})$ for lung cancer-specific mortality } \\
\hline & Deaths (total cases) & Age and stage adjusted & Multivariable adjusted $^{a}$ \\
\hline No diabetes & $1328(2208)$ & & \\
\hline Diabetes & $149(276)$ & $1.15(0.97,1.36)$ & $1.15(0.95,1.39)$ \\
\hline \multicolumn{4}{|c|}{ Duration of diabetes at cut-point of median value } \\
\hline $\begin{array}{l}<7 \text { years } \\
\geqslant 7 \text { years }\end{array}$ & $\begin{array}{l}76(143) \\
73(133)\end{array}$ & $\begin{array}{l}1.16(0.92,1.46) \\
1.13(0.90,1.44)\end{array}$ & $\begin{array}{l}1.15(0.90,1.48) \\
1.14(0.88,1.49)\end{array}$ \\
\hline \multicolumn{4}{|c|}{ Type of diabetic drugs in medication inventory } \\
\hline $\begin{array}{l}\text { Insulin (alone or with oral medication) } \\
\text { Metformin } \\
\text { Other drugs } \\
\text { Untreated/drugs unknown }\end{array}$ & $\begin{array}{l}28(46) \\
36(62) \\
34(56) \\
51(112)\end{array}$ & $\begin{array}{l}1.45(1.00-2.11) \\
1.34(0.96-1.87) \\
1.10(0.78-1.55) \\
0.96(0.72-1.27)\end{array}$ & $\begin{array}{l}1.52(0.99-2.34) \\
1.30(0.91-1.86) \\
1.18(0.81-1.70) \\
0.96(0.72-1.29)\end{array}$ \\
\hline \multicolumn{4}{|c|}{$\begin{array}{l}\left.{ }^{a} \text { Model further adjusted age at diagnosis ( }<55,55-59,60-64,65-69,70-74,>75\right) \text {, stage (localised, regional, and distant), for race/ethnicity (American Indian or Alaska Native, Asian or Pacific } \\
\text { Islander, Black or African American, Hispanic/Latino, non-Hispanic white, and other), education (high school or less, some college/technical training, college or some post-college, and master } \\
\text { or higher), BMI ( }<18.5,18.5-24.9,25.0-29.9,30.0-34.9,35.0-39.9,>40) \text {, physical activity (metabolic equivalent task (MET)-hours per week: }<5,5-<10,10-<20,20-<30,>30) \text {, alcohol } \\
\text { intake (non-drinker, past drinker, }<1 \text { drink per month, and current drinker-including frequency: }<1 \text { drink per month, } 1 \text { drink per month to }<1 \text { drink per week, } 1 \text { to }<7 \text { drinks per week, }>7 \\
\text { drinks per week), smoking (never, former, and current) and comorbidity }(0,1,2,3,4 \text {, or more) and different WHI clinical assignments. }\end{array}$} \\
\hline
\end{tabular}

\section{DISCUSSION}

Women with lung cancer and pre-existing diabetes had significantly poorer overall survival compared with women with lung cancer but without diabetes. Women with diabetes receiving insulin or metformin, or women who had longer duration of diabetes, had lower overall survival. Our study is the first prospective study to examine these relationships.

Experimental data suggest that metformin may improve lung cancer prognosis via radiosensitisation of NSCLC cells (Storozhuk et al, 2013) or via suppression of the detrimental effects of hyperinsulinemia on lung tumour growth (Algire et al, 2008). However, our data were not supportive of the hypothesised anticancer effects of metformin. Previous epidemiological data regarding the effects of types of diabetic therapy on lung cancer outcomes are sparse and provide inconsistent results. Two studies reported that metformin was associated with improved survival for participants with advanced lung cancer (Tan et al, 2011; Lin et al, 2015), but two other studies reported that metformin was associated with no benefit or even a worse prognosis (Mazzone et al, 2012; Ahmed et al, 2015). It is possible that the benefit of metformin observed in other studies is due to indication, as metformin is typically prescribed to those with short duration of diabetes as shown in our data, and without contraindicating factors (such as advanced age, liver, or kidney disease). Another possibility is that metformin may only benefit specific participants, such as people with advanced NSCLC.

Our data revealed a borderline significant increased risk for lung cancer-specific mortality for women who received insulin. The biological mechanism by which diabetes with insulin treatment increases lung cancer-specific mortality may involve the growth promoting effect of insulin (IGF-I) directly or indirectly (Richardson and Pollack, 2005; Ho et al, 2016). Another explanation is that diabetes may have indirect impacts on cancer outcome. For example, cancer participants with pre-existing diabetes may be diagnosed at advanced stages or be treated less aggressively than those without diabetes (van de Poll-Franse et al, 2007), which may contribute to increased cancer mortality. However, this proposed hypothesis was not supported by the current data that show no significant differences in lung cancer characteristics among women with and without diabetes.

The strengths of the study include the prospective design, rich data on demographic variables, potential risk factors and tumour characteristics, and physician-adjudicated causes of death. However, several limitations also deserve mention, including self-report 
diabetes, small sample size for specific diabetes medications, postmenopausal women, and lack of information regarding glucose control, diabetes progression, and untreated incident diabetes.

In conclusion, our large prospective study provides evidence that pre-existing diabetes is associated with poor overall survival among women with lung cancer, but do not support the hypothesis that metformin may have a protective effect among women with lung cancer and diabetes.

\section{ACKNOWLEDGEMENTS}

Research reported in this publication was supported by the National Cancer Institute of the National Institutes of Health under Award Number R15CA179463. The content is solely the responsibility of the authors and does not necessarily represent the official views of the National Institutes of Health. 'The WHI program is funded by the National Heart, Lung, and Blood Institute, National Institutes of Health, US Department of Health and Human Services through contracts HHSN268201100046C, HHSN268201100001C, HHSN268201100002C, HHSN268201100003C, HHSN268201100004C, and HHSN271201100004C.' We also request that you consult www.whi.org for exact wording if you include a description of the WHI trials in your manuscript. A short list of WHI investigators appears in the Supplementary Data Online.

\section{CONFLICT OF INTEREST}

The authors declare no conflict of interest.

\section{REFERENCES}

Ahmed I, Ferro A, Cohler A, Langenfeld J, Surakanti SG, Aisner J, Zou W, Haffty BG, Jabbour SK (2015) Impact of metformin use on survival in locally-advanced, inoperable non-small cell lung cancer treated with definitive chemoradiation. J Thorac Dis 7(3): 346-355.

Algire C, Zakikhani M, Blouin MJ, Shuai JH, Pollak M (2008) Metformin attenuates the stimulatory effect of a high-energy diet on in vivo LLC1 carcinoma growth. Endocr Relat Cancer 15(3): 833-839.

De Giorgio R, Barbara G, Cecconi A, Corinaldesi R, Mancini AM (2000) Diabetes is associated with longer survival rates in patients with malignant tumors. Arch Intern Med 160(14): 2217-2217.

Fine JP, Gray RJ (1999) A proportional hazards model for the subdistribution of a competing risk. J Am Stat Assoc 94(446): 496-509.

Garcia-Jimenez C, Garcia-Martinez JM, Chocarro-Calvo A, De la Vieja A (2014) A new link between diabetes and cancer: enhanced WNT/betacatenin signaling by high glucose. J Mol Endocrinol 52(1): R51-R66.

Hatlen P, Gronberg BH, Langhammer A, Carlsen SM, Amundsen T (2011) Prolonged survival in patients with lung cancer with diabetes mellitus. J Thorac Oncol 6(11): 1810-1817.

Hays J, Hunt JR, Hubbell FA, Anderson GL, Limacher M, Allen C, Rossouw JE (2003) The Women's Health Initiative recruitment methods and results. Ann Epidemiol 13(9 Suppl): S18-S77.

Ho GYF, Zheng SL, Cushman M, Perez-Soler R, Kim M, Xue X, Wang T, Schlecht NF, Tinker L, Rohan TE, Wassertheil-Smoller S, Wallace R,
Chen C, Xu J, Yu H (2016) Associations of insulin and IGFBP-3 with lung cancer susceptibility in current smokers. J Natl Cancer Inst 108: 7.

Jackson JM, Defor TA, Crain AL, Kerby T, Strayer L, Lewis CE, Whitlock E, Williams S, Bonds DE, Vitolins MZ, Rodabough RJ, Margolis KL (2013) Self-reported diabetes is a valid outcome in pragmatic clinical trials and observational studies. J Clin Epidemiol 66(3): 349-350.

Jackson RD, LaCroix AZ, Cauley JA, McGowan J (2003) The Women's Health Initiative calcium-vitamin $\mathrm{D}$ trial: overview and baseline characteristics of participants. Ann Epidemiol 13(9 Suppl): S98-106.

Langer RD, White E, Lewis CE, Kotchen JM, Hendrix SL, Trevisan M (2003) The Women's Health Initiative Observational Study: baseline characteristics of participants and reliability of baseline measures. Ann Epidemiol 13(9 Suppl): S107-S121.

Lin JJ, Gallagher EJ, Sigel K, Mhango G, Galsky MD, Smith CB, LeRoith D, Wisnivesky JP (2015) Survival of patients with stage IV lung cancer with diabetes treated with metformin. Am J Respir Crit Care Med 191(4): 448-454.

Margolis KL, Lihong Q, Brzyski R, Bonds DE, Howard BV, Kempainen S, Simin L, Robinson JG, Safford MM, Tinker LT, Phillips LS (2008) Validity of diabetes self-reports in the Women's Health Initiative: comparison with medication inventories and fasting glucose measurements. Clin Trials 5(3): 240-247.

Mazzone PJ, Rai H, Beukemann M, Xu M, Jain A, Sasidhar M (2012) The effect of metformin and thiazolidinedione use on lung cancer in diabetics. Bmc Cancer 12: 410.

Morss AS, Edelman ER (2007) Glucose modulates basement membrane fibroblast growth factor-2 via alterations in endothelial cell permeability. $J$ Biol Chem 282(19): 14635-14644.

Park SM, Lim MK, Shin SA, Yun YH (2006) Impact of prediagnosis smoking, alcohol, obesity, and insulin resistance on survival in male cancer patients: National Health Insurance Corporation Study. J Clin Oncol 24(31): 5017-5024.

Richardson LC, Pollack LA (2005) Therapy insight: influence of type 2 diabetes on the development, treatment and outcomes of cancer. Nat Clin Pract Oncol 2(1): 48-53.

Ritenbaugh C, Patterson RE, Chlebowski RT, Caan B, Fels-Tinker L, Howard B, Ockene J (2003) The Women's Health Initiative Dietary Modification trial: overview and baseline characteristics of participants. Ann Epidemiol 13(9 Suppl): S87-S97.

Shieh SH, Probst JC, Sung FC, Tsai WC, Li YS, Chen CY (2012) Decreased survival among lung cancer patients with co-morbid tuberculosis and diabetes. BMC Cancer 12: 174.

Stefanick ML, Cochrane BB, Hsia J, Barad DH, Liu JH, Johnson SR (2003) The Women's Health Initiative postmenopausal hormone trials: overview and baseline characteristics of participants. Ann Epidemiol 13(9 Suppl): S78-S86.

Storozhuk Y, Hopmans SN, Sanli T, Barron C, Tsiani E, Cutz JC, Pond G, Wright J, Singh G, Tsakiridis T (2013) Metformin inhibits growth and enhances radiation response of non-small cell lung cancer (NSCLC) through ATM and AMPK. Br J Cancer 108(10): 2021-2032.

Tan BX, Yao WX, Ge J, Peng XC, Du XB, Zhang R, Yao B, Xie K, Li LH, Dong H, Gao F, Zhao F, Hou JM, Su JM, Liu JY (2011) Prognostic influence of metformin as first-line chemotherapy for advanced nonsmall cell lung cancer in patients with type 2 diabetes. Cancer 117(22): 5103-5111.

van de Poll-Franse LV, Houterman S, Janssen-Heijnen MLG, Dercksen MW, Coebergh JWW, Haak HR (2007) Less aggressive treatment and worse overall survival in cancer patients with diabetes: a large population based analysis. Int J Cancer 120(9): 1986-1992.

WHI (2016) Women's Health Initiative. Manuals and Documents. Available at https://www.whi.org/researchers/studydoc/SitePages/ Manual\%20of\%20Operations.aspx (accessed on 10 April 2016).

Supplementary Information accompanies this paper on British Journal of Cancer website (http://www.nature.com/bjc) 